\title{
The Effect of COVID-19 on Land Transport Within the European Union and Guidelines for its Stable Development
}

\author{
By Svetla Tzvetkova ${ }^{1}$
}

\begin{abstract}
The COVID-19 pandemic delivered a devastating blow to land transport in Europe. The measures adopted for its containment drastically reduced services provided by railway transport and motor transport. Despite the limited demand during the pandemic, transport carriers did not cease their activities and proved their place in Europe's logistics chain. In order to overcome the negative effects of the crisis and restore mobility within the EU, transport firms require financial help and support. The present article reveals the negative results of the activity of passenger and cargo carriers within the EU in 2020 and makes inferences and recommendations for overcoming the negative situation faster on the basis of data presented by Eurostat about the impact that the COVID-19 pandemic has had on land transport. The presented data from Eurostat on the impact of the COVID-19 pandemic has served as a basis to make the respective inferences and indicate the fundamental guidelines for the stable development of land transport within the EU. Since railway transport is the safest, most secure and environmentally friendly type of transport, the focus is on the necessity for priority support of its activities.
\end{abstract}

Keywords: the effects of the COVID-19 pandemic on land transport, measures for overcoming the negative effects of the COVID-19 pandemic

\section{Introduction}

The outbreak of the COVID-19 pandemic at the beginning of 2020 had a profound negative effect on mobility in Europe. Land passenger and cargo transport freight activities were reduced considerably due to the imposed limitations and the measures adopted to contain the spread of the contagion in separate countries, as well as the drastic drop in the demand for land transport services which resulted from that. Commercial motor, passenger and cargo freights have been affected strongly by the bans introduced to limit the spread of the contagion, and the overall economic downturn. According to experts, the total losses for 2020 amount to approximately 1 trillion euro. At the same time, railway transport, which had sustained considerable damage as well, did not cease to operate, thus proving its resilience during times of crisis.

The global economic and social recovery of the community's economy after the COVID19 pandemic depends entirely on land transport functioning properly, which in turn depends on motor and railway carriers within the EU surviving and remaining on the transport market by continuing to service their customers.

The governments of each country and the EU's common transport policy will have to play 
a fundamental, key role in expediting the recovery from the crisis brought on by the COVID-19 pandemic. They need to mobilize their efforts and provide motor and railway carriers with the support they require.

\section{The Transport Policy of the EU}

Transport policy has held a key place in the common policies of the EU since its foundation. The significance of the common transport policy has been highlighted by the member states since the Treaty of Rome; an entire separate contractual portion is dedicated to it, thus making transport one of the first policies of the Community.

The transport connectivity of EU countries ensures their prosperity and territorial convergence. The sector holds a key place in the economic and social development of the Union and serves as a foundation for economic growth and creation of new jobs. In 2011 the EU Roadmap used this as a background to outline a strategy for a unified European transport space, calling for the Union to adopt a European transport policy that will provide sufficient clarity for encouraging investments and make the planning and building of new transport infrastructures possible (Tzvetkova \& Gadzhev, 2021).

The Union's priorities were originally focused on establishing a common transport market which allows freedom of providing services and opening transport markets. This goal was largely achieved because even national railway markets were gradually opened to competitors. Another purpose of opening the transport markets was to create conditions for fair competition for the individual types of transport, as well as the connections between them. For this reason, harmonization became increasingly important, encompassing the legal, normative and administrative regulations of the member states, as well as the technical, social and tax framework conditions within which the respective transport services are provided. The volume of cargo freights and passenger freights increased as a result of the liberalization and opening of the transport markets, the complete establishment of the European internal market, the elimination of internal borders and the drop in the prices of transport services.

In the context of ever-increasing greenhouse gas emissions from the transport sector, the topic of "stable mobility" became crucial, parallel with the opening of transport markets to competitors and the creation of trans-European transport networks. However, the dynamic and financially successful transport sector still faces multiple challenges related to stability.

The key role for the stable development of the all-European transport system, European integration, market expansion, employment and reducing the harmful effects of transport on the environment falls upon railway transport. Its undeniable advantages such as stability and safety make it the preferred type of transport for carrying out passenger and cargo freights within the European Union.

The purpose of the common transport policy is to guarantee competition, as well as the free supply of services. This requires harmonization of technical and administrative rules, as well as safety rules, which is crucial to achieving interoperability between separate national railway systems. The measures for environmental preservation and customer protection may also need a certain amount of harmonization, more specifically to avoid distortion of competition and to facilitate the entry of new enterprises on the market. One 
of the primary problems that the EU needs to solve is the creation of a co-dimensional ratio between transport types. The growing inequality between motor transport and railway transport needs to be overcome. The lack of good coordination and control of the competition between them will lead to a monopoly of motor transport, hence why the development of motor transport and other types of transport should be controlled and, if possible, limited, and the development of railway transport as the most ecological type of transport should be stimulated in order to give it a real opportunity to become a competitive alternative. This is the only way that the relative competitive advantages of the individual types of transport, including railways, can be developed and objectively assessed. Establishing more equal competitive conditions between transport types /intermodal competition/ is the necessary foundation for developing the competition within railways as well. It is the only possible direction along which its energy-saving, ecological and logistical advantages can be demonstrated (Tzvetkova, 2021a).

The spring of 2020 and the spread of the coronavirus throughout Europe tested many sectors, including "Transport". The drop in the number of travels was observed in the first quarter as a result of the multitude of limitations enforced by authorities in individual EU countries.

Following the beginning of the crisis and the resulting consequences for transport, on June 192020 the European Parliament passed a resolution titled "Transport and Tourism in 2020 and Beyond (2020/2649(RSP)", which called for rapid, short-term and long-term support for the transport sector and the tourism sector in order to ensure their survival and competitiveness. After March 2020, the Parliament passed several legislative resolutions through an emergency procedure - resolutions aimed at combating the immediate negative consequences of the pandemic on the transport sector (European Parliament, 2020a).

The agencies of the European Commission recommended that the member states sign public service contracts within the meaning of the procurement directives. Additionally, uniform rules regarding Services of General Interest (SGI) were implemented. They arrange the conditions under which compensation for SGI can be provided. Provided that all requirements are fulfilled, no notification is required in accordance with state aid rules. The goal of the proposed Regulation COM (2020)0260 was to temporarily lift the rules determined in Directive 2012/34/EC, allowing national authorities and interested parties in the railway sector to deal more easily with a number of negative consequences from the COVID-19 pandemic: cancelling, reducing or postponing railroad access fees for using the railway infrastructure as well as exemption from reservation fees (European Commission, 2020a).

Based on the tremendous potential of railway transport, the European Parliament's Committee on Transport and Tourism (TRAN) accepted the proposition to name 2021 the European Year of Rail. The proposition was also announced in support of the objectives of the Green Deal, which partially called for expediting the transition towards stable and intelligent mobility. Although the transport sector produces a quarter of the amount of greenhouse gas emissions in the EU, the Union aims for a $90 \%$ reduction by 2050 (European Parliament, 2020b).

As part of the Green Deal, the European Commission calls for allocating a considerable amount of the $75 \%$ share of land cargo freights currently carried out by road to railway 
and water transport (Tzvetkova, 2021b). It should also be emphasized that it is the only type of transport to record a drop in the amount of harmful $\mathrm{CO}_{2}$ emissions in recent years, parallel with increasing the volume of freights carried out by it. Furthermore, it is proof of European engineering experience and part of European heritage and culture.

2021, the European Year of Rail, will help expedite the modernization of railways as the most environmentally friendly and secure land transport. This, in turn, will attract more passengers and consignors who will prefer it over motor transport. This will be the first full year during which the rules negotiated within the fourth legislative package in the field of railway transport will be implemented across the entire EU. Additionally, 2021 marks several important anniversaries for railway transport: the 20th anniversary of the first legislative package in the field of railway transport, the 175th anniversary of the first rail connection between two EU capitals (Paris-Brussels), as well as the 40th anniversary of high-speed trains in France (TGV) and the 30th anniversary of the Intercity Express (ICE) of German railways (European Commission, 2020b).

\section{The Impact of COVID-19 on Motor Transport}

Scientific studies on the impact that COVID-19 has had on the various types of transport show that each type of transport reacts differently to the changes in the economic environment. The Transportation Expert Panel (TEP) conducted a study among 340 transport experts from 100 countries from August to September 2020 (Petkov \& Yanev, 2021).

Since the measures for containing the COVID-19 pandemic forced millions of people to remain in their homes, motor transport activities ceased almost completely for hundreds of thousands of small and medium enterprises. In addition to the limited urban services, some companies have also recorded a drop of at least $90 \%$ in the activity of inter-urban services and a 100\% drop for transport services related to tourism. Furthermore, a drastic drop has been observed in the taxi industry, with some taxi operators noting that their earnings have dropped by $80 \%$, and the majority of their activity has been terminated because of the transport limitations imposed across the entire EU and the sharp drop in the demand for passenger transport services. In order to adapt to this new reality, most motor carriers have reduced their prices significantly in order to make their freights more accessible to everyone.

Motor cargo freights have also been severely affected by the crisis. Most of them kept operating throughout the entire year following the start of the pandemic, but suffered serious losses due to the reduced earnings and the inability to service all running costs such as bills and fees. The business reductions and the lack of return cargo, as well as the presence of irregularities within the sector also compounded their state further. Certain suppliers demand cash payment upon delivery, and most customers fail to pay on time. All of these negative effects that have resulted from the crisis lead to risk of bankruptcy and inability to fulfil credit obligations. The deterioration of the financial indicators is a sign of motor transport firms that have purchased their rolling stock on credit terminating their activities this year.

The tremendous losses that motor carriers within the European Union have suffered between the start of the COVID-19 pandemic and late November 2020 are presented in 
Table 1 below.

Table no 1: The Impact of COVID-19 on Motor Transport

\begin{tabular}{|l|c|c|}
\hline Motor transport & $\begin{array}{c}\text { The impact of COVID-19 } \\
\text { (loss of earnings) during the } \\
\text { March-June period }\end{array}$ & $\begin{array}{c}\text { The impact of COVID-19 } \\
\text { (loss of earnings) during the } \\
\text { June-November period }\end{array}$ \\
\hline Passenger motor transport & 94 billion Euro & 94 billion Euro \\
\hline Cargo motor transport & 75 billion Euro & 125 billion Euro \\
\hline
\end{tabular}

Source: IRU Intelligence, November 2020 report

Table 1 makes it clear that motor transport passenger carriers have suffered a loss of 94 billion euro during the March-November 2020 period. It is apparent that motor cargo transport has suffered even greater losses compared to passenger transport, namely -125 billion euro.

From the information presented in the table it becomes evident that for a period of seven months, during the COVID-19 pandemic, motor transport has suffered serious losses and its recovery will take a long period of time with the help of financial support and relief alone.

The data available in Table 1 indicates that the COVID-19 pandemic has had a profoundly negative impact on motor transport, hence why the risk of certain smaller transport firms terminating their freight activities is real.

\section{The Impact of COVID-19 on Railway Transport}

During the first period of the pandemic in spring 2020, railway operators shut down the majority of international passenger trains. The number of passengers who use inland railway transport dropped by up to $90 \%$ compared to the previous year. A certain number of new participants on the passenger freight market were forced to cease their activities.

Railway cargo freight operators also reported a drop in freight volumes in the first months of the pandemic as a result of multiple enterprises either reducing or completely shutting down production due to the pandemic's impact.

The levels of demand and transport volumes for passenger and cargo freights remained low in the summer of 2020 as well. During the fall of 2020, the second wave of the pandemic forced many countries to adopt additional restrictive measures in relation to citizens' mobility, thus compounding the work of land transport operators even further. Based on data provided in Eurostat and other institutional sites, media and internal sources about the passenger flows and cargo flows of railway freights, the European Commission analyzed and drew conclusions about the effect of the pandemic on railway transport in the EU's member states, noting that: ,The restrictions imposed on the free movement of people have had severe repercussions for the railway transport sector during March, April and May 2020. Although the member states have been gradually lifting these restrictions since the month of May, demand has continued to drop until June 2020" (European Commission, (2020c).

As a whole, the pandemic has had a stronger effect on passenger freight services 
compared to cargo freight services, despite the differences among individual member states.

The train $/ \mathrm{km}$ ratio of services carried out during the March-September 2020 period in comparison to the March-September 2019 period is presented in Table 2 below.

Table no 2: The train $/ \mathrm{km}$ ratio of services carried out during the March-September 2020 period in comparison to the March-September 2019 period

\begin{tabular}{|l|c|}
\hline Type of transport & $\begin{array}{c}\text { The train } / \mathrm{km} \text { ratio of carried out during the March-September } \\
2020 \text { period in comparison to the March-September 2019 period }\end{array}$ \\
\hline Passenger railway transport & $16,9 \%$ (a 16,9\% drop) \\
\hline Cargo railway transport & $11,1 \%$ (an 11,1\% drop) \\
\hline
\end{tabular}

Source: Eurostat

Table 2 makes it clear that both segments have been severely affected by the first wave of the pandemic, with the drop in services carried out by passenger transport being 5,8\% higher compared to cargo railway transport.

The ratio of the number of trains which have traversed the railway network during the March-September 2020 period in comparison to the March-September 2019 period is presented in Table 3 below.

Table no 3: The ratio of the number of trains during the March-September 2020 period in comparison to the March-September 2019 period

\begin{tabular}{|l|r|}
\hline Type of transport & $\begin{array}{r}\text { The ratio of the number of trains which have traversed the railway } \\
\text { network during the March-September } 2020 \text { period in comparison } \\
\text { to the March-September } 2019 \text { period }\end{array}$ \\
\hline Passenger railway transport & $11,1 \%$ (a drop in the number of passenger trains) \\
\hline Cargo railway transport & $8,2 \%$ (a drop in the number of cargo trains) \\
\hline
\end{tabular}

Source: Eurostat

The data presented in Tables 2 and 3 about the services carried out in train $/ \mathrm{km}$ and the number of trains which have traversed the railway network of EU countries paints a clear picture of just how vast and disastrous the effect of the COVID-19 pandemic has been on railway passenger and cargo transport. This presents a challenge for the whole sector and suggests that huge difficulties lie ahead for land railway transport and its efforts to restore its activity to its state prior to the pandemic and come out of the negative situation successfully.

The other data presented in Eurostat about passenger/kilometers and ton/kilometers in railway passenger and cargo transport during the first two quarters of 2020 clearly shows the impact of the crisis on the demand for passenger and cargo freight services in railway transport. It should be noted that Austria and Belgium are not included in the passenger/kilometers data for EU-27; Belgium is not included in the ton/kilometers data for EU-27, either. 
Table no. 4 - The ratio of the work (in \%) carried out by passenger railway transport (passenger $/ \mathrm{km}$ ) and cargo railway transport $($ ton $/ \mathrm{km})$ in the first two quarters of 2020 in comparison to the first two quarters of 2019

\begin{tabular}{|l|c|c|}
\hline Types of railway transport & $\begin{array}{c}\text { The ratio of the work carried out } \\
\text { during the first quarter (January- } \\
\text { March) of 2020 in comparison to } \\
\text { the same period (January-March) } \\
\text { in 2019 }\end{array}$ & $\begin{array}{c}\text { The ratio of the work carried out } \\
\text { in the second quarter (April- } \\
\text { June) of 2020 in comparison to } \\
\text { the same period (April-June) in } \\
2019\end{array}$ \\
\hline Passenger railway transport & $16,8 \%$ & $71,2 \%$ \\
\hline Cargo railway transport & $8,3 \%$ & $15,9 \%$ \\
\hline
\end{tabular}

Source: Eurostat

Table 4 makes it clear that traffic in passenger/kilometers has dropped by $16,8 \%$ in the first quarter of 2020 compared to the first quarter of 2019. The second quarter of 2020 shows a $71,2 \%$ drop compared to the second quarter of 2019.

Regarding cargo railway transport, traffic in ton/kilometers has dropped by $8,3 \%$ in the first quarter of 2020 compared to the first quarter of 2019. The second quarter of 2020 has recorded a 15,9\% drop compared to the second quarter of 2019.

The data available up to June 2020 proves the tremendous impact on demand volumes during the first wave of the pandemic. Furthermore, it provides information about a hypothesis concerning the possible consequences of the second wave of the pandemic which hit the sector at the beginning of the summer.

Passenger freight services included in the obligations for carrying out public services, as well as commercial passenger freight services of individual countries have been affected by the consequences of the pandemic to varying degrees. More specifically, commercial services continue to struggle in their efforts to return to their 2019 levels:

- In some countries, commercial passenger freight services had been put on hold for a few months in 2020, more specifically in areas where passenger flows related to commercial passenger freight services were already low even before the pandemic;

- Even in the cases of more stable commercial services, railway traffic levels had been too low to guarantee the survival of railway enterprises.

According to the Commission's economic prognosis from fall 2020, although economic activities in Europe have been affected by a severe shock in the first half of the year, they have begun their recovery in the third quarter due to the gradual lifting of the restrictive measures. Still, the recovery from the COVID-19 pandemic during the fall, along with the re-introduction of restrictive measures by national authorities, has led to a new drop in economic activities. The prognosis has been made in conditions of deep uncertainty, considering the gradual tightening of the measures in the field of public health in the fourth quarter of 2020 and their gradual loosening in 2021 and 2022, but production in the Euro area and the EU is not expected to return to its pre-pandemic levels in 2022.

The last available quick prognosis of the Commission about the consumer trust index published in November 2020 shows negative values for the Euro area (-17,6 points) and the EU (-18,7 points); both values are below their long-term average levels of $-11,2$ and 10,6 respectively, not to mention they have dropped in comparison to the month of October (European Commission, 2020d). 
The Commission's economic trust index presents a similar situation. Said indicator has been affected to a particularly strong degree during the first wave of the pandemic, and it only began to recover in May. The latest available studies of business and consumers show that trust recovery is in a state of stagnation in the Euro area and the EU in October 2020, which is when the continent was hit by the second wave of the pandemic.

Although the member states implement more specific and less rigorous restrictive measures during the second wave of the pandemic, these measures continue to have negative effects on railway traffic, and the financial balance of railway enterprises is still affected by the impact of the first wave of the pandemic.

The outbreak of the second wave of the pandemic impeded the fast recovery of railway traffic, more specifically with regard to railway passenger freight services. The member states once again imposed limitations on mobility in October and November. The data which was available until September 2020, as well as the data on customers' trust, shows that the effect of improving the public health situation will probably be felt considerably later than expected, considering that such an improvement is expected in the first half of 2021, for example, due to available vaccines. As such, railway traffic levels are expected to remain lower than the ones prior to the pandemic, at least until the halfway point of next year.

\section{Inferences and Recommendations}

Motor carriers play a key role in restoring the economy, the community as a whole, and its supply chains. Despite being the primary pollutant of the environment, motor transport makes up $80 \%$ of commercial and land transport in the EU, providing mobility and logistics services. Liquidity will be the most pressing issue for motor carriers in 2021. The risk of failure in duty and bankruptcy will be very high. The dark economic perspective and the huge losses in the entire sector will bring many enterprises to bankruptcy, which is why they require urgent financial support, more specifically gratuitous aid, flexible schemes for paying insurance premiums, tax and fee relief, etc. All of this is a priority for retaining their positions in the business, as well as their survival on the transport market. After the COVID-19 crisis, land transport operators will play a crucial role in satisfying people's mobility needs during the economic recovery phase, hence why the survival of the sector and its subsequent recovery should be a priority.

Compared to motor trans port, the railway sector has always been more resilient in times of crisis. Most operators have transferred the traffic capacity from sea ports to intraEuropean transport, and railway transport has adapted to carrying the types of goods which usually are not part of its primary activity. For its part, the EC has provided green lanes for border checkpoints to shorten the timeframes for the transportation of goods. Railway transport faces challenges involving the delays in industrial production, which is why the measures adopted through state support will have to prevent the extinction of certain operators and railways' capacity. The crisis caused by the pandemic is a call to action for increasing the boldness of the TEN-T project. A modern, effective and stable infrastructure system will improve European competitiveness and efficiency. It is necessary to place railway transport at the center of the reconstruction phase, and provide adequate funding for innovation activities to develop an intelligent, efficient, innovative 
and reliable railway sector.

Railway transport needs to be placed at the center of the reconstruction phase and adequate funds should be provided for innovation activities in order to develop an intelligent, effective, innovative and reliable railway sector. It is an undeniable fact that railway transport is the most environmentally friendly type of transport which, as a result of its functioning, has the lowest amount of greenhouse gas emissions and its negative effect on the environment is minimal (Tzvetkova, 2021c).

The aforementioned statement is supported by Figure 1 (shown below) which presents the percentage of harmful greenhouse gas emissions resulting from the functioning of each individual type of transport.

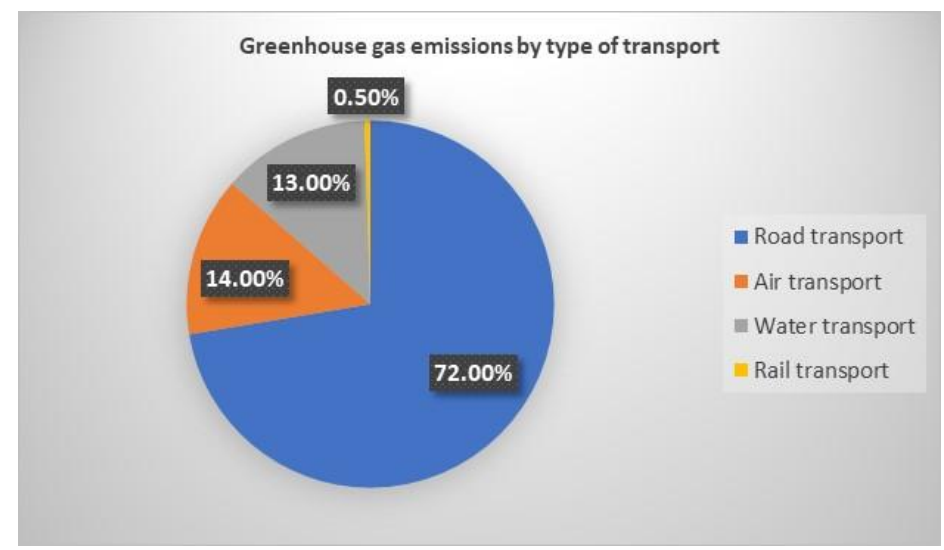

Figure no.1: Greenhouse gas emissions by types of transport, 2020

Source: NSI

Figure 1 makes it evident that motor transport is the undisputed leading pollutant of the atmosphere $-72 \%$ of greenhouse gas emissions, followed by air transport $-14 \%$, and water transport $-13 \%$, whereas railway transport has registered approximately $1 \%$.

It is obvious that railway land transport is one of the most stable forms of passenger and cargo land transport. Because it is largely electrified, it is the only type of transport that has reduced its emissions considerably in the past decades.

Another thing that makes railway transport the safest type of land transport is the small number of incidents that have occurred as a result of its functioning: only 0.1 casualties per 1 billion passenger $/ \mathrm{km}$ have been caused by rail accidents; for reference, 0.23 casualties have been caused by bus accidents, 2.7 by car accidents and 38 by motorcycle accidents (2011-2015).

All of these advantages make railway transport the safest, most environmentally friendly and energy efficient type of transport which connects people and businesses across the entire EU through the Trans-European Transport Network (TEN-T) whose development contributes to effective connectivity, reduction of traffic jams, noise levels and pollution, as well as the improvement of transport safety (Gatovski, 2021).

Railway transport should take over a considerable amount of the freights carried out by motor transport $(75 \%$ of domestic cargo), which will help reduce the emissions of the "Transport" sector and contribute to the stable development of land transport. 
In the short run, the transport sector will have to deal with COVID-19. However, the role of railway transport in the lives of European citizens will have to be re-examined by keeping the conditions for stability and competitiveness at the core of the future vision for Europe. Measures that will help railway transport adapt to the new reality will have to be introduced. The current period of shortened schedules should be used as a chance to focus on maintaining and renewing the current rolling stock. A stable infrastructure with highly automated operations needs to be developed. The introduction of electronic ticketing systems, overcoming challenges in the management of finances, and information security will guarantee strong financial stability.

The EU's institution and industry need to picture "the new normal" again. It is necessary to secure funding for research and development activities: the railway industry needs to be at the center of European citizens' mobility; reducing public funds would impede the development of railway transport in the EU. Policies that encourage economic growth and ecology need to be coordinated. The encouragement of economic recovery, which simultaneously calls for changes in behavior such as encouraging walking and cycling, is crucial at the present moment. In this context, public transport, especially railway transport, could play a fundamental role.

The European Commission's new industrial strategy for Europe, as well as the positions of the "Green Deal" regarding railway transport predate the COVID-19 crisis, and as such is not ready to deal with consequences from it. Therefore, we will need to have the courage to not only maintain the industry's global competitiveness, but to provide a new political vision for railway transport as well.

The challenges that the European railway system faces during and after the pandemic necessitate the support of a strong all-European research programe for railway transport:

- Cooperation between universities and research centers needs to be strengthened in order to ensure innovative decisions in railway technology and improve the competitiveness of European studies;

- European universities and research institutions need to have their say in EU decisions which involve railway transport in order to ensure that all key participants in the European railway sector share the strategic vision;

- All participants in the transport sector, including universities and research centers, have to share strong political guidelines. Large enterprises cannot manage the vision for the future European railway sector by themselves.

The main fields which require funds include:

- Digitalization and automation of vital processes, depending on manual operations;

- Multi-dimensional analysis of urban mobility models and operational supply and demand;

- Research for reduction of operating expenses through new transport policies and legal actions;

- Interdisciplinary research for providing guidelines related to railway transport during a health crisis;

- Traceability of logistics through training and predictive models capable of offering prognoses for sources of distribution in transport, related to the optimization of resources for the railway community; 
- Interdisciplinary research for developing and using self-cleaning materials in trains.

As it turns out, railway transport is less susceptible to interruptions by other freights and can play an effective role in ensuring mobility and combating the spread of the virus (Greentech 2021).

The severe economic and social global crisis brought on by the COVID-19 pandemic will provoke the necessity to focus more attention on: the lack of foresight in terms of supporting carbon-based fossil fuels; the modal transition from motor transport and air transport to railway transport as the most environmentally friendly type of transport; the necessity to improve the rolling stock of railway transport and the quality of provided transport services, which will ensure better connectedness for European citizens and goods, as well as a more stable future for Europe.

\section{Conclusion}

In 2020 global economy fell into recession as a result of the COVID-19 pandemic; the restoration of pre-crisis production levels is expected to take at least three more years. The economic and social recovery of Europe depends primarily on the recovery of the individual economic sectors, among which the "Transport" sector is key, and more specifically, the successful functioning of land transport which satisfies the needs for cargo freights and passenger freights within the Union.

At present, the "Transport" sector faces multiple challenges which involve overcoming the negative effect of the COVID-19 pandemic, as well as the level of greenhouse gas emissions recorded within the EU, which is still high. For this reason, the European Commission (EC) has proposed, as part of its plan for the Green Deal, that special attention be given to railway transport this year.

Despite the fact that motor transport is the life force of the Community's economy and continued to operate during the crisis, supplying shipments and mobility networks to all points of the Union, it remains the leading pollutant of the environment. Railway transport, which is more environmentally friendly and more energy efficient by comparison, also proved during the COVID-19 pandemic that it can provide fast transportation of basic goods such as food, medicine and fuel under extreme circumstances. Railway transport is also capable of solving other pressing issues regarding mobility within the Community such as: climate neutrality, energy efficiency, stability during crises and freight safety. It connects remote areas, ensuring internal and crossborder convergence of European regions. However, despite all the advantages of this type of transport for carrying cargo and passengers within the EU, at present only $7 \%$ of passengers and 11\% of goods travel via railway transport. The obsolete infrastructure, outdated business models and high maintenance costs are part of the obstacles that need to be overcome in order to create a unified European railway space (Euro reporter, 2021a). Therefore, one of the fundamental priorities of Europe's transport policy in 2021 is aimed towards the stable development of railway transport by highlighting its benefits for people, the economy and the climate. If the goals of the "European Green Pact" are to be achieved, railway transport will have to take up a larger share of passenger freights and cargo freights within the EU.

In accordance with achieving the goals of the European Green Pact, the EU announced 
2021 as the year of railway transport in order to work towards achieving climate neutrality by 2050. With a budget of about 8 million euro, this type of land transport will be popularized on a European level (European Union, 2020).

The first day of 2021 marked the start of the European Year of Rail. The initiative of the European Commission will highlight the benefits of railway transport as a stable, intelligent and safe means of transportation. The various activities will make railway transport the center of attention all throughout 2021 across the entire continent in order to encourage citizens and businesses alike to use railway transport and contribute to the EU's Green Deal objective of achieving climate neutrality by 2050.

Adina Vălean, the European Commissioner for Transport, made the following statement: "Our future mobility needs to be stable, safe, convenient and accessible. Rail offers all of that and more! The European Year of Rail gives us the opportunity to rediscover this type of transport. Through various activities, we will use this occasion to help railway transport realize its full potential. I invite all of you to take part in the European Year of Rail." (Euro reporter, 2021b).

\section{References}

European Commission (2020), Flash Consumer Confidence Indicator for EU and Euro Area. Retrieved from https: //ec.europa.eu/info/sites/default/files/flash consumers 202011 en.pdf;

European Commission (2020), Recovery of euro area and EU Economic Sentiment halting - Employment, Expectations down. Retrieved from: https://ec.europa.eu/commission/presscorner/detail Len/ip 20 1269;

European Commission (2020), Autumn 2020 Economic Forecast: Rebound interrupted as resurgence of pandemic deepens uncertainly. Retrieved from: https://ec.europa.eu/info/sites/info/files/economyfinance/ecfin forecast autumn 2020 overview en.pdf;

European Commission (2020), Summer 2020 Economic Forecast: An even deeper recession with wider divergences. Retrieved from https: //ec.europa.eu/info/sites/default/files/full bcs 202010 en.pdf;

European Union (2020), Regulation of the European Parliament and of the Council, (EU) 2020/698. Retrieved from http://data.europa.eu/eli/reg/2021/267/oj;

European Parliament (2020), European Parliament Resolution on Transport and Tourism in 2020 and Beyond (2020/2649(RSP). Retrieved from: https://www.europarl.europa.eu/doceo/document/B-9-20200182 EN.html;

Euro reporter, Independent media, Economics (2021), The journey begins - 2021 the European's Year of Railway Transport", Retrieved from: https://bg.eureporter.co/frontpage/2021/01/14/2021-theeuropean-year-of-rail/;

Euro reporter, Independent media, Economics (2021), The European's Year of Railway,_Retrieved from: https://bg.eureporter.co/frontpage/2021/01/05/the-journey-begins-2021-is-the-european-yearof-rail/;

Gatovski, I., (2021), “The Challenges and Perspectives in the Development of Railway Infrastructure - a Factor for the Transport Connectivity of the Republic of Bulgaria", Scientific Conference "The Challenges and Perspectives in the Development of Railway Transport", UNWE's Publishing Complex, Sofia, ISSN: 978-619-232-450-6, pp. 42-51;

Greentech (2021), On line Journal for transport, "2021 will be the year of the railway in Europe", Retrieved from https://greentech.bg/archives/79730;

Petkov, I., Yanev, M., (2021), "The influence of COVID-19 on intermodal transport and perspectives for development", Jubilee Scientific Conference commemorating the 70th anniversary of the establishment of the "Economics of Transport and Energy" department and specialty, "Transport Connectivity 2020", October 29 2020, UNWE's Publishing Complex, Sofia, ISSN: 978-619-232451-3, pp.66-72; 
Tzvetkova (2021) “The EU's policy for the de development of railway transport - 2021 - the European year of rail", Scientific Journal Entrepreneurship, Volume: IX, Issue: 1, Year: 2021, ISSN: 2738-7402, DOI: 10.37708/ep.swu.v9i1.3, pp. 36-44;

Tzvetkova, S., Gadzhev, P., (2021), The effect of COVID -19 pandemic on low cost companies in

Europe", Scientific Conference "The Challenges and Perspectives in the Development of Railway Transport", UNWE's Publishing Complex, Sofia, ISSN: 978-619-232-450-6, pp. 25-36. 